ORIGINAL RESEARCH PAPER

\section{A STUDY ON EPIDEMIOLOGY OF DIABETIC RETINOPATHY AMONG DIABETIC PATIENTS ON MEDICAL THERAPY IN A TERTIARY CARE HOSPITAL}

\section{Ophthalomology}

KEY WORDS: Diabetic retinopathy(DR), Diabetes mellitus(DM) Proliferative diabetic retinopathy (PDR), Non proliferative diabetic retinopathy (NPDR), clinically significant macular edema (CSME), outpatient department (OPD), fundus fluorescei angiography (FFA), Rapid assessment of avoidable blindness (RAAB)

\section{Dr. R. Shanthi} Malar

\section{Dr. S. Srinivasan}

\section{Dr. R. Jebin David*}

\section{Dr.V. K. Monica}

M.D, D.A, The Dean/ DME (OSD), Professor of Emergency Medicine, Government Kilpauk Medical College And Hospital, Chennai-600010.

Professor, M.S, D.O., Head of The Department, Department of Ophthalmology, Government Kilpauk Medical College And Hospital, Chennai-600010.

M.B.B.S, II Year Postgraduate, M.S (ophthalmology) Department of Ophthalmology Government Kilpauk Medical College And Hospital Chennai-600010.*Corresponding Author

M.B.B.S, II Year Postgraduate, M. (ophthalmology), Department of Ophthalmology, Government Kilpauk Medical College And Hospital, Chennai600010.

AIM:

1. To determine the prevalence of diabetic retinopathy among diabetic patients on medical treatment.

2. To determine the risk factors contributing to the development of diabetic retinopathy.

3. To study the epidemiology of diabetic retinopathy patients in relation to age, sex, duration of diabetes, type of diabetes and the type of medical treatment BACKGROUND:

Diabetic Retinopathy is one of the leading cause for visual morbidity among diabetic patients.

Diabetic retinopathy can be broadly classified into non-proliferative diabetic retinopathy (NPDR) and proliferative diabetic retinopathy (PDR).

MATERIALS AND METHODS: A cross sectional study was conducted on 600 consecutive individuals who presented or was referred to our ophthalmology department from October 2021 to December 2021. All subjects underwent a comprehensive eye examination including brief history taking, slit lamp examination and dilated fundus examination using slit lamp biomicroscopy with 90D lens.

RESULTS: 600 diabetic patients were screened and 24 (4\%) of them were diagnosed with diabetic retinopathy. CONCLUSION: Strict control of glycaemic level through medical therapy and periodical eye screening should be advised to all diabetic patients especially in patients more than 40 years of age to reduce the complications of diabetic retinopathy.

\section{INTRODUCTION:}

Diabetic Retinopathy is one of the leading cause for visual morbidity among diabetic patients. Diabetic Retinopathy is a microvascular complication of diabetes mellitus. About two third of patients with T2DM and almost all TIDM patients develop diabetic retinopathy over a period of time ${ }^{[1]}$.

According to WHO the current estimated prevalence of diabetes mellitus in the adult population in India is 72.96 million cases. According to WHO, 31.7 million Indians had diabetes mellitus during the year 2000 and the prevalence was expected to increase up to 79.4 million by the year $2030^{[2]}$. It is estimated that DR was responsible for $1.06 \%$ of blindness and $1.16 \%$ of visual impairment globally in 2015 .

In India, the union health ministry's first national diabetes and diabetic retinopathy survey (2015-2019) has revealed that the prevalence of diabetic retinopathy is $16.9 \%$ and the prevalence of vision threatening diabetic retinopathy is $3.6 \%$. Diabetes mellitus is defined as fasting plasma glucose of more than $126 \mathrm{mg} / \mathrm{dl}$ or $\mathrm{HbAlc}$ more than $6.5 \%$ in two readings. Diabetic retinopathy can be broadly classified into non-proliferative diabetic retinopathy (NPDR) and proliferative diabetic retinopathy (PDR). NPDR is in turn classified into very mild NPDR, mild NPDR, moderate NPDR, severe NPDR, and very severe NPDR ${ }^{[3]}$.

The purpose of collecting survey data is to estimate the burden of diabetic retinopathy in the population and to develop intervention programs for control of blindness based on community needs for eye health care providers and also to monitor and prioritize the existing eye health programs when needed with regards to visual morbidity and blindness.

In our study, people of all ages already on medical line of management for diabetes mellitus were screened to estimate the prevalence of diabetic retinopathy changes in the patients.

Some of the causes of avoidable blindness are cataract, glaucoma, river blindness, trachoma, uncorrected refractive error, diabetic retinopathy, age related macular degeneration, vitamin A deficiency, measles, ophthalmia neonatorum, retinopathy of prematurity, amblyopia, strabismus and ocular injury.

\section{Aim OfThe Study}

1. To determine the prevalence of diabetic retinopathy among diabetic patients on medical treatment.

2. To determine the risk factors contributing to the development of diabetic retinopathy.

3. To study the epidemiology of diabetic retinopathy patients in relation to age, sex, duration of diabetes, type of diabetes and the type of medical treatment

\section{Method Of Study}

Cross Sectional Study

Study Period:

October 2021 -December 2021

\section{Inclusion Criteria}

1. All patients attending the diabetology outpatient department were included in the study.

2. All patients with diabetes referred from other specialty departments like general medicine, obstetrics and gynecology, nephrology, general surgery and other departments were included in the study.

3. All patients with diabetes attending the ophthalmology 
OPD were included in the study.

\section{Exclusion Criteria}

1. Patients who were not willing were excluded from the study

2. Patients on irregular treatment were excluded from the study

3. Patients with both eyes corneal opacity, mature cataract and other media opacities were excluded from the study.

\section{Justification ForThe Study:}

Determining the risk factors contributing to the development of diabetic retinopathy among diabetic patients helps in formulating government programs that can reduce the incidence of diabetic retinopathy and also to diagnose them earlier so that appropriate treatment can be started at the earliest.

\section{Limitations OfThe Study:}

Since our survey was conducted within two months, we were not able to assess various indicators like positive family history of diabetes mellitus, BMI status, lipid profile, systemic complications associated with diabetic retinopathy. Some of the patients were not willing to participate in the study.

\section{Conflict Of Interest:}

No personal conflict or interest in the study.

\section{Consent OfThe Patient For Study:}

Informed written consent in the patient's preferred language was obtained from the participants.

\section{Materials Used}

The following materials were used in our study - snellen's visual acuity chart, schiotz tonometer, slit lamp biomicroscopy with 90D lens, direct ophthalmoscope, indirect ophthalmoscope, applanation tonometer and canon fundus camera.

\section{METHODS}

During the study period, a team of ophthalmologists were deployed to the diabetology OPD to screen the patients for diabetic retinopathy. Detailed history regarding the diabetes and other systemic comorbidities were taken along with any ocular symptoms. Visual acuity was evaluated using the snellen's chart which was appropriately placed in the diabetology OPD. Other anterior segment findings were evaluated using torch light examination and the findings were later confirmed using slit lamp examination. All patients were screened for IOP using schiotz tonometer and in special cases using applanation tonometer.

Informed consent was obtained from the patients. After dilatation, fundus examination was done using indirect ophthalmoscope. Those patients who were diagnosed with diabetic retinopathy were sent to the ophthalmology OPD and the picture of their fundus were taken. Patients with PDR were informed to attend the OPD on a later date for undergoing fundus fluorescein angiography (FFA).

Diabetic patients attending ophthalmology OPD and referred from other departments were also examined using the above methods. The data was compiled in a master chart and was consolidated according to the variables. The results of the study are based on the data acquired during the study period.

\section{Variables:}

The variables considered in this study are sex distribution, age distribution, duration of diabetes, referred department, type of treatment and type of retinopathy.

\section{RESULTS:}

In our study 600 diabetic patients were screened, out of which 24 patients ( $4 \%$ ) were diagnosed with diabetic retinopathy.
Sex Distribution:

\section{Sex Distribution}

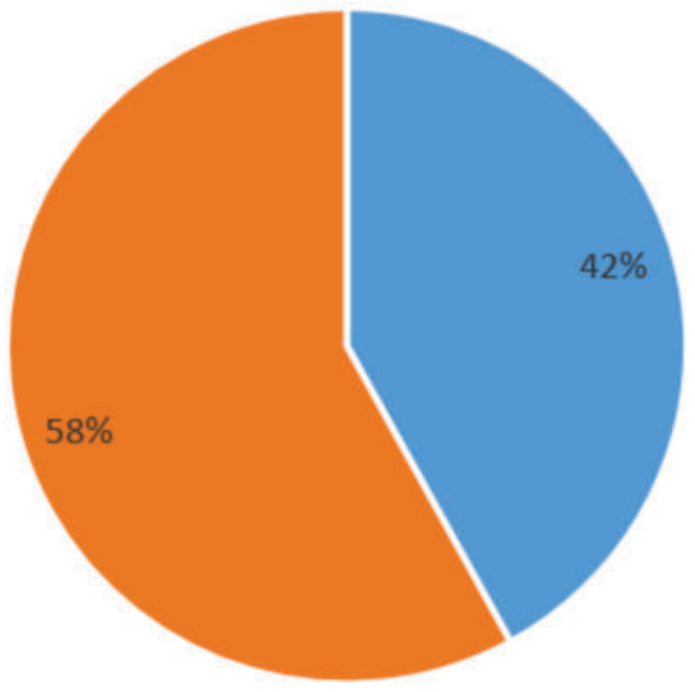

\section{- Male = Female}

Figure 1: shows the sex distribution of the diabetic patients screened in terms of percentage

Among 600 diabetic patients screened, $42 \%$ were males and remaining $58 \%$ were females. There was no significant sexual preponderance identified in our study.

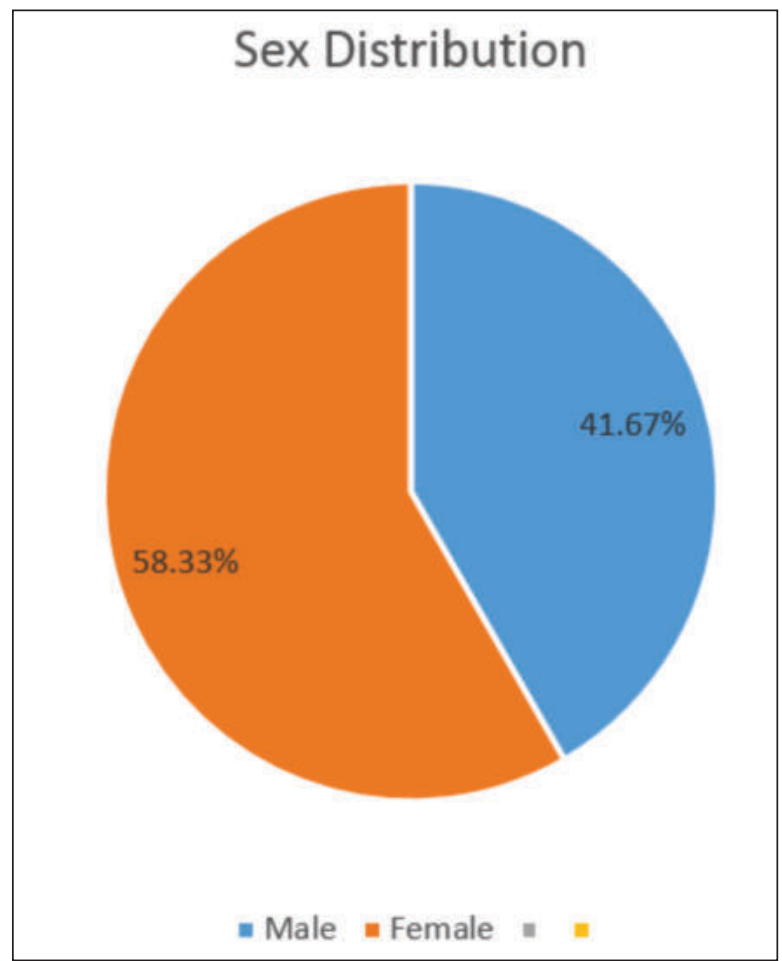

Figure 2: shows the sex distribution of the diabetic retinopathy patients detected in terms of percentage

Among 24 diagnosed diabetic retinopathy patients, 41.67\% 
were males and remaining $58.33 \%$ were females. There was no sexual preponderance identified in our study.

\section{Age Distribution:}

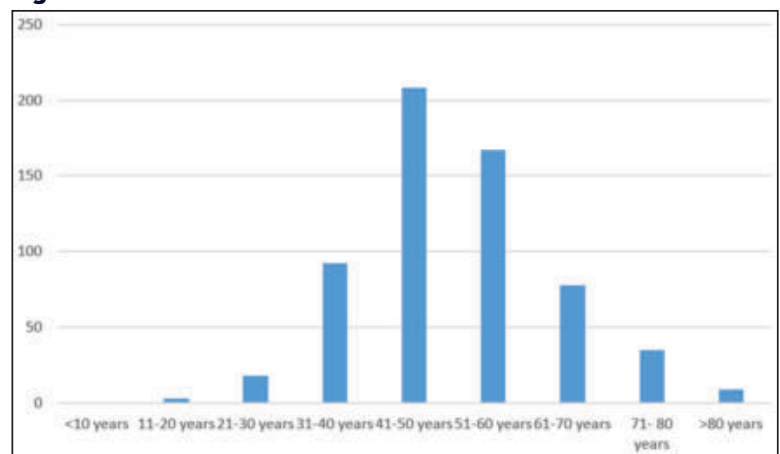

Figure 3: table showing age distribution of diabetic patients screened for diabetic retinopathy.

Among 600 patients screened, the age range varied from 13 years to 84 years. Majority of patients (34.67\%) in our study belonged to the age group 41-50 years followed by 51-60 years $(27.83 \%)$.

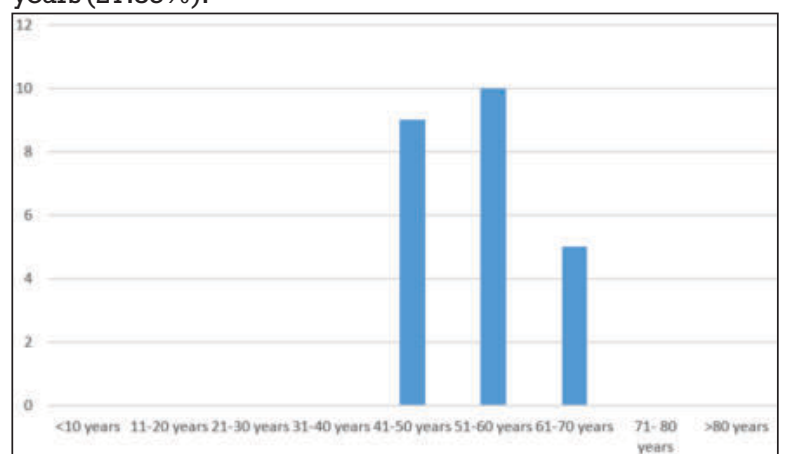

Figure 4: table showing age distribution of diabetic patients diagnosed with diabetic retinopathy.

Majority of patients diagnosed with diabetic retinopathy (41.67\%) in our study belonged to the age group 51-60 years followed by $41-50$ years $(37.5 \%)$.

\section{Duration of Diabetes:}

\begin{tabular}{|l|l|l|}
\hline Duration of Diabetes & Number of Patients & Percentage (\%) \\
\hline
\end{tabular}

\begin{tabular}{|l|l|l|}
\hline$<5$ & 47 & 7.53 \\
\hline $5-10$ & 85 & 14.17 \\
\hline $11-15$ & 108 & 18 \\
\hline $16-20$ & 54 & 9 \\
\hline $21-25$ & 3 & 0.5 \\
\hline $26-30$ & 2 & 0.33 \\
\hline$>30$ & 1 & 0.17 \\
\hline Total & 600 & 100 \\
\hline
\end{tabular}

Figure 5: shows the duration of diabetes among the patients screened

In our study, among 600 patients screened, the duration of diabetes ranged from newly diagnosed to 32 years. Majority of the patients (18\%) had duration of diabetes around 11-15 years followed by $14.17 \%$ of patients who had the duration of diabetes around 5-10 years.

\begin{tabular}{|l|l|l|}
\hline Duration of Diabetes & Number of Patients & Percentage (\%) \\
\hline
\end{tabular}

\begin{tabular}{|l|l|l|}
\hline$<5$ & 6 & 25 \\
\hline $5-10$ & 7 & 29.17 \\
\hline $11-15$ & 7 & 29.17 \\
\hline $16-20$ & 3 & 12.5 \\
\hline $21-25$ & 1 & 4.17 \\
\hline $26-30$ & 0 & 0 \\
\hline$>30$ & 0 & 0 \\
\hline Total & 24 & 100 \\
\hline
\end{tabular}

Figure 6: shows the duration of diabetes among patients diagnosed with diabetic retinopathy

In our study, majority of the patients $(29.17 \%)$ had duration of diabetes around $11-15$ years and 5-10 years each, followed by $12.5 \%$ of patients who had the duration of diabetes around $16-$ 20 years.

In our study; out of the 600 diabetic patients screened, majority of patients $(32.83 \%)$ were on combined OHA and $\mathrm{HI}$. Out of the 24 patients diagnosed with diabetic retinopathy $(62.5 \%)$ were on combined $\mathrm{OHA}$ and $\mathrm{HI}$.

In our study $94.67 \%$ patients had T2DM and out of the 24 patients diagnosed with diabetic retinopathy, all of them had T2DM.

$5.33 \%$ patients had TIDM and DR changes were not detected in them in our study.

\begin{tabular}{|l|l|l|l|}
\hline Type of Retinopathy & RE & LE & Percentage (\%) \\
\hline Very mild NPDR & 7 & 9 & 37.5 \\
\hline Mild NPDR & 3 & 4 & 16.67 \\
\hline Moderate NPDR & 6 & 6 & 25 \\
\hline Severe NPDR & 1 & 3 & 12.5 \\
\hline Very Severe NPDR & 1 & 1 & 4.17 \\
\hline Proliferative Diabetic Retinopathy & & & \\
\hline Advanced Diabetic Eye Disease & 1 & 1 & 4.17 \\
\hline CSME & 2 & 2 & 8.33 \\
\hline Total & 19 & 24 & 100 \\
\hline
\end{tabular}

Figure 7: shows the distribution of diabetic retinopathy patients according to the ETDRS classification

In our study, out of the 24 diabetic patients diagnosed with diabetic retinopathy, majority of the patients $(37.5 \%)$ were diagnosed with very mild NPDR. $25 \%$ of the patients were diagnosed with moderate NPDR, $16.67 \%$ patients were diagnosed with mild NPDR and only $4.17 \%$ of the patients were diagnosed with advanced diabetic eye disease.

Only $8.33 \%$ of the patients has clinically significant macular edema (CSME).

Both eyes are affected in 19 patients and left eye alone is affected in 5 patients. This shows that the prevalence of bilateral diabetic retinopathy is $79.17 \% .20 .83 \%$ had left eye involvement.

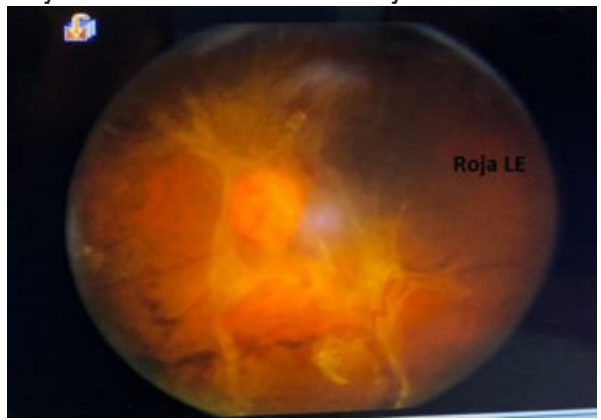

Figure 8: showing fibrovascular bands over the disc, was diagnosed as advanced diabetic eye disease.

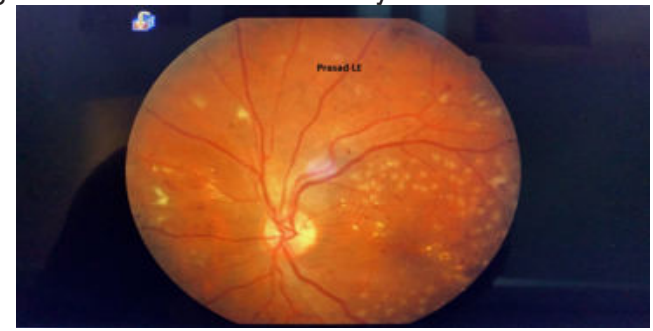

Figure 9: showing laser marks of grid laser photocoagulation of the left eye, patient was diagnosed with severe NPDR with CSME 


\section{DISCUSSION:}

Diabetic retinopathy is a morbid microvascular complication of diabetes affecting one in three persons with diabetes. Most common cause for vision loss due to diabetes among diabetic patients is due to DR.

Diabetes mellitus is a microvascular disease and the primary targets are kidneys, nerves and retina. Other organs like heart, central nervous system and peripheral vessels may also be affected by macroangiopathic complications of diabetes. The microvascular pathological changes in diabetic retinopathy are leukostasis, vascular leakage due to breakdown of blood retinal barrier and histologic changes within the vasculature.

In the previous studies conducted for the prevalence of diabetic retinopathy, following were the results. Namperumalsamy P et al.- $10.84 \%^{[4]}$, Rema et al. - $7.3 \%{ }^{[5]}, \mathrm{V}$ Narendran et al. $-26.2 \%{ }^{[6]}$, Dandona et al. $-22.4 \%{ }^{[7]}$, Raman R et al. - $18 \%{ }^{[8]}$, Wisconsin epidemiological study - $28.8 \%{ }^{[9]}$. Kornerup in 1957 found $47 \%$ of patients with diabetes were having diabetic retinopathy.

In our study, we screened 600 diabetic patients already on medical line of management. Patients presented to our hospital either in the diabetology OPD $(91.67 \%$,) Eye OPD or other departments like general medicine, general surgery, OBG and nephrology department.

Among them 24 patients were diagnosed with diabetic retinopathy of various severity. Most of the patients (37.5\%) were diagnosed with very mild NPDR. The next category which had the most patients (25\%) was moderate NPDR and $16.67 \%$ patients had mild NPDR. NPDR patients detected $95.83 \%$ and advanced diabetic eye disease detected is $4.17 \%$. One patient with severe NPDR and one patient with advanced diabetic eye disease had CSME.

From our study, we came to the conclusion that about 58.34\% of patients with diabetic retinopathy had duration of diabetes around 5-15 years. And more than 20 years only $4.17 \%$ of the patients were diagnosed with DR. Hence review schedule based on the severity of the DR has to be followed for routine eye examination including fundus examination.

Our data revealed that most of the patients diagnosed with diabetic retinopathy (41.67\%) belonged to the age group 5160 years followed by $41-50$ years $(37.5 \%)$. That means we can conclude that diabetic retinopathy commonly affects diabetic patients in their $5^{\text {th }}$ or $6^{\text {th }}$ decade.

All the patients who were diagnosed with diabetic retinopathy had type 2DM.

Among 24 diagnosed diabetic retinopathy patients, 41.67\% were males and remaining $58.33 \%$ were females. Hence we can infer that there is no significant sexual preponderance when it comes to prevalence of diabetic retinopathy. This is in contrast to some studies which showed male preponderance $(2: 1)[10]$.

In our study out of the 24 patients diagnosed with diabetic retinopathy, $62.5 \%$ were on combined OHA and $\mathrm{HI}$ and $91.67 \%$ of the patients were referred from diabetology OPD.

\section{Review schedule for nonproliferative diabetic retinopathy:}

Very Mild NPDR - 1 year

Mild NPDR -6 to 12 months

Moderate NPDR -3 to 6 months

Severe NPDR-less than 3 months

Very severe NPDR-less than 1 month

According to literature most relevant risk factors for diabetic retinopathy development are disease duration, poor glycemic control, presence of hypertension, high body mass index and poor socioeconomic status. Myopia seems to have no impact on the development of diabetic retinopathy ${ }^{[1]]}$.

\section{CONCLUSION:}

In our diabetic retinopathy screening survey in 600 diabetic patients on antidiabetic treatment in tertiary care hospital, the number of diabetic retinopathy changes detected was 24 . Among the 4\% prevalence of diabetic retinopathy reported in our study, the visual impairment due to advanced diabetic retinopathy is $16.67 \%$ and blindness prevalence is $4.17 \%$.

$34.67 \%$ of people in our study belonged to the age group 41 50 years and $27.83 \%$ between $51-60$ years. Reported diabetic retinopathy changes were $41.67 \%$ in $51-60$ years and $37.5 \%$ between 41-50 years.

Strict control of glycaemic level and periodical eye screening protocol to be followed depending upon the stages of DR and it should be advised to all diabetic patients. The role of vitroretinal surgeon by laser photocoagulation, intravitreal anti-VEGF agents, vitrectomy and other retinal surgeries for vision threatening complications in $\mathrm{DR}$ can be performed to prevent blindness.

Eye care services for DR can be provided to the needed persons in time effectively so the eye morbidity due to $D R$ can be reduced. While conducting DR screening, multi system related morbidity and mortality due to diabetes mellitus can be reduced if they undergo treatment by the concerned speciality doctors as and when required.

Hence this epidemiological analysis reveals that diabetic retinopathy screening to be continued in all parts of India periodically and simultaneously with other blindness control programs like glaucoma and cataract related RAAB survey. This is to assess the area where increased prevalence of diabetes mellitus, the most needed DR screening program area identification and also identification of DR changes in patients with visual impairment or vision threatening complications.

Accordingly planning actions can be charted for avoidable blindness to reduce visual morbidity due to DR and its complications.

\section{REFERENCES:}

1. Prevention of Blindness from Diabetic Retinopathy. Report of a WHO Consultation, Geneva;November, 2005.

2. Wild S, Roglic G, Green A, Sicree R, King H. Global prevalence of diabetes: Estimates for the year 2000 and projections for 2030. Diabetes Care 2004; 27:1047-53.

3. Early Treatment Diabetic Retinopathy Study Research Group. Grading diabetic retinopathy from stereoscopic color fundus photographs: an extension of the modified Airlie House classification: ETDRS report number 10. Ophthalmology. 1991;98(suppl):786-806.

4. Namperumalsamy P, Kim R, Vignesh TP, Nithya N, Royes J, Gijo T, et al. Prevalence and risk factors for diabetic retinopathy: $\mathbb{A}$ population-based assessment from Theni District, South India. Postgrad Med J 2009;85:643-8.

5. Rema M,Premkumar S, Anitha B,Deepa R, Pradeepa R,Mohan V. Prevalence of diabetic retinopathy in urban India: The Chennai urban rural epidemiology study (CURES) eye study, I. Invest OphthalmolVis Sci 2005; 46:2328-33.

6. Narendran V, John RK, Raghuram A, Ravindran RD, Nirmalan PK, Thulasiraj RD. Diabetic retinopathy among self-reported diabetics in Southern India: $A$ population based assessment. Br J Ophthalmol 2002;86:1014-8.

7. Dandona L, Dandona R,Naduvilath TJ, McCarty CA, Rao GN. Population based assessment of diabetic retinopathy in an urban population in Southern India. BrJ Ophthalmol 1999;83:937-40.

8. Raman R, Rani PK, Reddi Rachepalle S, Gnanamoorthy P, Uthra S, Kumaramanickavel G, et al. Prevalence of diabetic retinopathy in India: Sankara Nethralaya diabetic retinopathy epidemiology and molecular genetics study report 2. Ophthalmology 2009; 116:311-8.Klein R, Klein BE, Moss SE, Davis MD, DeMets DL.

9. The Wisconsin epidemiologic study of diabetic retinopathy. III. Prevalence and risk of diabetic retinopathy when age at diagnosis is 30 or more years. Arch Ophthalmol 1984; 102:527-32.

10. Bodansky HJ, Cudworth AG, Drury PL et al; Risk factors associated with severe proliferative retinopathy in IDDM-Diabetes Care 1982;5;97-100.

11. Rand L, Krowleswki A, Warram J. Multiple risk factors for PDR Diabetes 1984: 33:92A 